\title{
Quality of sleep of technical employees of university set-up: a study from urban India
}

\begin{abstract}
Aim: There is high report of unrecognized sleep disorders in corporate set-up in India, however, rarely there is any report on what about the government organized set-up. This study aimed to assess quality of sleep of employees across age and gender.

Methods: One hundred permanent employees of university and colleges equally divided into sex and two age groups (30-45 years and 46-60 years respectively) were assessed on Pittsburg Sleep Quality Index.

Results: Quality of sleep got affected across both gender and ages where females $(58 \%)$ were identified as having significantly severe sleep related problems in comparison to the males $(32 \%)$ at $\mathrm{p}=0.026$. Both Higher age (FHA) and Lower age females (FLA) had significant severe sleep problem $(60 \% \& 56 \%$ respectively) in comparison to the male counterpart (Both MHA \& LHA 32\%) at $\mathrm{p}=0.12$.

Conclusion: Quality of sleep is of concern at government urban set-up in India which can have impact on work performance, personal life etc. Special attention on sleep awareness might be needed to minimize the impact of sleep related stress.
\end{abstract}

Keywords: employees, quality of sleep, gender difference, psychological conditions, sleep related disorder
Volume 2 Issue 2 - 2018

\author{
Parag Dutta,' Prasanta Kumar Roy² \\ 'School of Social Sciences, Kolkata Regional Centre, India \\ ${ }^{2}$ Department of Clinical Psychology, Institute of Psychiatry, India
}

Correspondence: Prasanta Kumar Roy, Department of Clinical Psychology, Institute of Psychiatry, 7 D. L. Khan Road, Kolkata, 700025, India, Tel +9I-94334846 I2,

Email prasanta.roy@gmail.com

Received: March 03, 2017 | Published: March 23, 2018
Abbreviations: SRD, sleep related disorder; FLA, female with lower age (30-45 years); MLA, male with lower age (30-45 years); FHA, female with higher age (46-60 years); MHA, male with higher age (46-60 years)

\section{Introduction}

Poor sleep quality can be the result of stress and anxiety in general population. In clinical set up, sleep disturbances are important symptoms of many medical and psychological conditions. Studies have reported that poor sleep or Sleep Related Disorders (SRD) may be associated with frequent sick leave, difficulties in interpersonal relationships, problem in job related activities in addition to poor physical and psychological health., ${ }^{1,2}$ Early identification and appropriate management of these SRDs may help to prevent cardiovascular diseases, psychological disorders, and even accidents. ${ }^{3,4}$ Sleep pattern gets affected by changing lifestyle, use of mobile at night, eating habits, work profile, leisure activities including different life stresses to result in SRDs. In the rapidly changing India, SRDs are emerging as important health issues by affecting nearly one fifth of apparently healthy age group. ${ }^{5}$

A 2012 survey on corporate employees in India by Associated Chambers of Commerce and Industry of India showed that nearly $78 \%$ sleep less than six hours a day, leading to severe sleep disorders. ${ }^{6}$ In another survey in 2013 it was found that $93 \%$ of Indians are sleep deprived, getting less than 8 hours per night, $58 \%$ believe their work suffers due to lack of adequate sleep, $11 \%$ take leave from work because of lack of sleep, $11 \%$ have fallen asleep at work due to a poor night's sleep. The same survey reports that lack of sleep also affects family relationships according to $19 \%$ and $15 \%$ wake up over stress at work. Important is that $33 \%$ Indians snore. However, only 2 per cent of Indians discuss their lack of sleep with a physician.
In India the Government sector employees are having significantly less stress in comparison to the private or corporate sectors ${ }^{8,9}$ may be due to various factors including greater job security. Moreover, majority of employees associated with university official job are not into shift work and are bound by limited job target. Many of the risk factors associated with workplace are absent for the employees working in some specific universities run by the Government. This study was an attempt if at all we need to pay attention to this less vulnerable workforce with respect to quality of sleep that is considered to be associated with occupational stress. ${ }^{10}$ At the same time there is a strong ignorance on sleep related problem in India that may further aggravate the problem to have poor quality of life. Thus assessing the quality of sleep in these employees will give us an idea about the magnitude of the problem even in the general mass living in urban India. Further, one research from Europe suggests that female gender and younger age employees experience higher level of occupational stress ${ }^{11}$ whereas, a recent Indian study with similar population found just opposite. ${ }^{12}$ Due to direct association between occupational stress and quality of sleep, it would be interesting to see whether gender and age can have any differential influence on the sleep quality.

\section{Methods}

This was a cross sectional comparative study of quality of sleep across gender and age of employees working at a university in a metro city of India. A stratified random sampling method was followed with equal proportion at each sub-group.

\section{Sample}

100 university employees consisting of 50 males and 50 females were considered for the study. In each group, two subgroups, comprising of 25 employees, was made, varying in age group of 
30-45years, and 46-60 years (Figure 1). Participants were full time non-teaching permanent employees at various technical or officer posts working under a university run by Government in a metro city of India. Subjects having known physical disabilities, experience of loss or grief in past 6 months, recent history of physical trauma and acute medical illness or known terminal illness were not considered for this study. The total number represented more than $20 \%$ of the total employees of the particular category of that university.

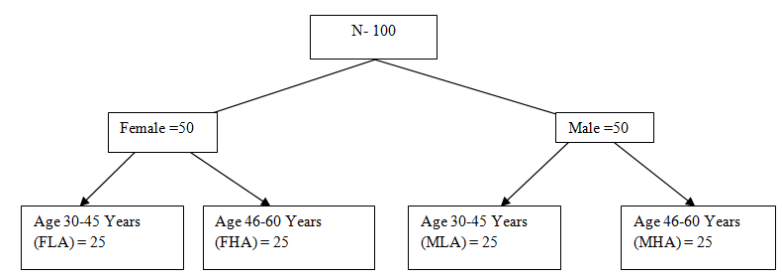

Figure I Distribution of sample.

\section{Measures}

The Pittsburg Sleep Quality Index (PSQI): It is a self rated questionnaire which assesses sleep quality and disturbances over a month time interval. Nineteen individual items generate seven "component" scores: subjective sleep quality, sleep latency, sleeps duration, habitual sleep efficiency, sleep disturbances, use of sleep medication, and day time dysfunction. The sum of scores for these seven components yields one global score. Acceptable measures of internal homogeneity, consistency (test-retest reliability), and validity were obtained. A global PSQI score $>5$ yielded a diagnostic sensitivity of $89.5 \%$ and specificity of $86.5 \%$ in distinguishing poor and good sleepers. Quality of sleep is also graded as mild, moderate and severe when PSQI scores are less than 5 , equal to 5 and greater than 5 respectively. ${ }^{13,14}$

\section{Statistical Analysis}

For categorical variables related to gradation of sleep quality score chi-square statistics were calculated. Gender and Age related differences for continuous scale scores of PSIQ global and component scales was analyzed using student's $t$ test using SPSS windows version 16.

\section{Results}

The distribution of quality of sleep was similar across gender and two age groups ( $\mathrm{t}=.894, \mathrm{p}=.347$ and $\mathrm{t}=1.64$. $\mathrm{p}=0.204$ respectively).

When the 4 study groups were compared with respect to the severity of sleep difficulties (Table 1), result was statistically significant $\left(x^{2}=\right.$ $16.27, p=0.012$ ) with majority of female of both lower and upper age $(56-60 \%)$ reported severe level of sleep difficulty, whereas, $60 \%$ of male of lower age reported no sleep difficulty. Moderate to Severe sleep problem was noticed in $64 \%$ of FLA, $40 \%$ of MLA, $72 \%$ of FHA and $68 \%$ of MHA. Post-hoc analysis based on adjusted residual scores suggest that number of cases in the MLA group was significantly higher than expected for No sleep difficulty, whereas, number of cases in the MHA was significantly higher than other groups for Moderate sleep difficulty. For Severe sleep difficulty number of cases was on the higher side though not significant for both FLA and FHA.

When age was not considered, gender distribution of sleep related problem was also significant $\left(x^{2}=7.26, p=0.026\right)$. Number of female was significantly high (adjusted residual $=2.6$ ) for Severe sleep difficulty. Almost half of the female reported severe sleep related difficulties $(58 \%)$ whereas, $46 \%$ of the male did not report any sleep difficulty. Thirty two percent however reported severe problem (Table 2).

Table I Comparison of 4 groups on severity of sleep difficulties

\begin{tabular}{|c|c|c|c|c|c|c|c|}
\hline & & \multicolumn{4}{|l|}{ Group } & \multirow{2}{*}{$\chi^{2}(\mathrm{Df}=6)$} & \multirow{2}{*}{$P$ value } \\
\hline & & FLA & MLA & FHA & MHA & & \\
\hline \multirow{6}{*}{ Sleep difficulty } & No difficulty & $9(36.0 \%)$ & $15(60.0 \%)$ & $7(28.0 \%)$ & $8(32.0 \%)$ & \multirow{6}{*}{16.274} & \multirow{6}{*}{0.012} \\
\hline & $\begin{array}{l}\text { [Adjusted } \\
\text { Residual] }\end{array}$ & -0.4 & 2.5 & -1.3 & -0.8 & & \\
\hline & Moderate & $2(8.0 \%)$ & $2(8.0 \%)$ & $3(12.0 \%)$ & $9(36.0 \%)$ & & \\
\hline & $\begin{array}{l}\text { [Adjusted } \\
\text { Residual] }\end{array}$ & -1.3 & -1.3 & -0.6 & 3.1 & & \\
\hline & Severe & |4(56.0\%) & $8(32.0 \%)$ & $15(60.0 \%)$ & $8(32.0 \%)$ & & \\
\hline & $\begin{array}{l}\text { [Adjusted } \\
\text { Residual] }\end{array}$ & 1.3 & -1.5 & 1.7 & -1.5 & & \\
\hline
\end{tabular}

Abbrevations: FLA, Female Lower Age; MLA, Male Lower Age; FHA, Female Higher Age; MHA, Male Higher Age

Table 2 Comparison of gender with respect to severity of sleep difficulties

\begin{tabular}{|c|c|c|c|c|c|}
\hline \multirow{2}{*}{ Variable } & & \multicolumn{2}{|l|}{ Sex } & \multirow[t]{2}{*}{$\chi^{2} \mathrm{Df}=2$} & \multirow{2}{*}{ p-value } \\
\hline & & Female & Male & & \\
\hline \multirow{3}{*}{ Sleep difficulty } & No difficulty & $16(32.0 \%)$ & $23(46.0 \%)$ & & \\
\hline & Moderate & $5(10.0 \%)$ & $\mathrm{II}(22.0 \%)$ & 7.262 & 0.026 \\
\hline & Severe & $29(58.0 \%)$ & $16(32.0 \%)$ & & \\
\hline
\end{tabular}




\section{Discussion}

The participants in this study were technical employees working in the day shift in a University set-up run by Government in a metro city of India. The primary aim was to assess degree of sleep related disturbances of the employees across age and gender. It was expected that less stressful environment of university set-up might have lesser number of sleep related problems; however, $45 \%$ of employees (female \& male reported 58\% and 32\% respectively) had subjective complain of severe sleep related problems that can be associated with or manifested as complain of night-time insomnia, stress, anxiety, depression etc. ${ }^{3}$ In a 2017 Spanish Population Study ${ }^{15}$ the prevalence of poor quality of sleep was found to be $38.2 \%$ and in our sample it was even higher may be due to population difference or presence of stress. In consistent with the above study we also found that higher age is associated with poorer quality of sleep in male, whereas, in female, all are observed to be more vulnerable irrespective of their age. The worse sleep quality found in women is consistent with other literature too; ${ }^{9,10}$ Women take up multiple roles in family and work that might result into more preoccupation and less priority to sleep as they need to prioritize other responsibilities of family (taking care of children, spouse, older adults) and work roles. Though Tandon et al. ${ }^{12}$ reported higher work stress in male than female in one of the Indian studies, there is no reason to accept that finding as our study also indirectly pointed out. Our study highlights that poor sleep quality is also evident in around half of the technical employees of university that may be a warning issue and might interfere with overall productivity of employees.

\section{Conclusion}

The study highlights the need to address employee's sleep quality in the organized set-up where a majority show difficulties. The factors might be work related stress or may be personal stress. Exploring into the causes of stress is beyond the scope of this work as it followed cross sectional design with smaller sample size. However, even in government set-up more awareness related to sleep needs to be designed to avoid adverse consequences.

\section{Acknowledgements}

None.

\section{Conflict of interest}

The authors declared that there are no conflicts of interest.

\section{References}

1. Doi Y, Minowa M, Tango T. Impact and correlates of poor sleep quality in Japanese white-collar employees. Sleep. 2003;26(4):467-471.

2. Colten HR, Altevogt BM, editors. Sleep disorders and sleep deprivation: An unmet public health problem. Washington DC: National Academies Press; 2006:67-209.

3. Gilling JC. Are sleep disturbances risk factors for anxiety, depressive and addictive disorders? Acta Psychiatr Scand Suppl. 393:39-43.

4. Johnson LC, Spinweber CL. Good and poor sleepers differ in Navy performance. Mil Med. 1983;148(9):727-731.

5. Panda S, Taly AB, Sinha S, et al. Sleep-related disorders among a healthy population in South India. Neurol India. 2012;60(1):68-74.

6. ASSOCHAM. 2012.

7. Phillips Health Survey. 2013.

8. Rana RM. A comparative study of job stress of Government and Private Employees. International Journal of Research in Humanities and Social Sciences. 2014;2(2):51-53.

9. Ganapa P, Sreedevi A. A comparative study of work related stress among Government and Private school teachers of Kurnool Town. International Journal of Public Mental Health and Neurosciences. 2015;2(1):27-32.

10. Utsugi M, Saijo Y, Yoshioka E, et al. Relationships of occupational stress to insomnia and short sleep in Japanese workers. Sleep. 2005;28(6):728 735 .

11. Antoniou AS, Polychroni F, Vlachakis AN. Gender and age differences in occupational stress and professional burnout between primary and high school teachers in Greece. J Manag Psychol. 2006;21:682-690.

12. Tandon JK, Mahaur C, Gupta A. Effect of Age and Gender on Occupational Stress: A Study on Teaching Fraternity. International Journal of Engineering Technology, Management and Applied Sciences. 2014;2(2):41-46.

13. Buysse DJ, Reynolds CF, Monk TH, et al. The Pittsburgh sleep quality index: A new instrument for psychiatric practice and research. Psychiatry Res. 1989;28(2):193-213.

14. Mollayeva T, Thurairajah P, Burton K, et al. The Pittsburgh sleep quality index as a screening tool for sleep dysfunction in clinical and non-clinical samples: A systematic review and meta-analysis. ¡Sleep Med Rev. 2016;25:52-73.

15. Madrid-Valero JJ, Martinez-Selva JM, Ribeiro do Couto B, et al. Age and gender effects on the prevalence of poor sleep quality in the adult population. Gac Sanit. 2017;31(1):18-22. 